\title{
Nathan Felde
}

Northeastern University

Boston, United States of America

n.felde@northeastern.edu

\section{Eventual Design for an Emergent World}

\section{Abstract}

Are we at a punctuation point in the evolution of design practices? The ascendance of modern design practices, over the last 100 years, to popular and pervasive application, is fraught with questions about benefits and limits. In light of persistent social injustice, political strife and looming ecological danger, a more extensive accounting of the work of designers is needed, if only to craft a proper manifesto for proceeding with our work. By extrapolating recent trends in the evolution of design practices, a meta-practice of "eventual" design is envisioned, to call attention - beyond form of artifacts, process of service, and quality of experience - to the entailments, actions and etiquette of events, and their eventual consequences. The "event" is identified as a fruitful entry point for forensic reconnaissance into causes, effects and consequences in this terra incognita. An event lab and instrument are sketched, with intentions to 1. identify aesthetic causes, social effects and systemic consequences of design; 2 . formulate a common etiquette between and amongst people and with technology; and 3. model and monitor interdependence and sensitivity within the logistics of our human project and ecology of living systems to avoid detrimental or disastrous consequences.

\section{Keywords}

Design, Consequence, Events, Aesthetics, Etiquette

\section{Introduction}

Design, in essence, is a kind of wishful thinking combined with audacity and ingenuity. As designers, given any evidence of the worlds we inhabit, we can, with classic "blues" mentality, recite a list of ills, flaws and shortcomings that dismay. So, when we contemplate a new approach to design, consistent with our times, it is instinctual to not look away from past disasters and present dangers of human making and doing. But it is axiomatic that we imagine optimistic goals.

Design is also a kind of guessing game in which the guesses include ideas about the remote existence of the "other"; ideas that are presumptuous and biased by personal experience; ideas that use anecdotes and asymptotes to conjure archetypes and prototypes with impunity, and are realized with a peculiar ingenuity and determinism.

Design is also often conflated with deciding. Origami provides a clarifying metaphor: While folding moves determinedly toward an explicit exclusive formal expression by deciding, designing opens new possibilities of form, by cutting. Design prototypes first subvert and violate the norm, before assimilation of the preferred is replicated.

While design is often cited as a means to goodness, beneficial change, and betterment of life, there is a 
dark side to this noble tradition; this speculative studio practice of intentionally making mistakes and fixing some of them; this mutative operation with putative benefits. It seems imperative, as we proceed, to not ignore the penalty of misunderstanding each "other" and conflicts inherent in the rise of a single species to dominate nature with "human" nature.

Modern design principles have had tremendous influence over the last one hundred years on most design practices and arguably constitute a major cultural force shaping infrastructure and implements of the modern world. But as demands and desires of one species threaten the existence, natural resources and habitable environment of other species, we risk epic eventual calamity. Philosopher Stanley Cavell said it well as "our capacity to do harm has exceeded our capacity to do good." [1]

Designers and their clients, largely absolved of liability, are nonetheless instrumental in delivering this moment. Even conscientious designers invoking methods of social and environmental science in their research lack sufficient means to understand or account for derivative, long-term, far-reaching or unintended consequences. The question goes begging: How should we account for the shortcomings, limitations and constraints of design practices?

Designers have been, and remain, active and integral to capitalism, industrialization and globalization. Flaws in capitalism, however, exacerbate disparity and rupture the fabric of everyday life. Excesses of human habit and density of human habitat proceed toward depletion and saturation of our ecology. Corruption and regulation distort and circumvent intended results. Design happens.

Sublimated violence inhabits our infrastructure. Errors that can rapidly propagate unknown risks, persistent threats and real danger to living systems have a new velocity: the speed of light. Digital connectivity accelerates toward ubiquity throughout the logistics of our human project. Interdependence amongst humans, and with and within technology, grows, both tantalizing and ominous.

In the late 1980 s, the entire national telecommunications infrastructure in the United States faced total collapse from a cascade of errors spawned from a single typo in one million lines of code. How will we avoid catastrophes of such proportions as the cybernetic future expands like the universe and evidence of its constitution fades?

Every single material object belies the violence of its origins, its production and eventual dangers of its use, abuse, distribution, abandonment and ultimate interment. Manifest, latent, buffered or muted, violence constitutes a real terror of our existence and needs a remedy. Is there a link between error and terror we do not see?

Questions face designers (and their clients) as to whether existing design processes can be applied to this emergent world or even address failures from the past. Can we better understand the social and ecological consequences of "designing" the world? Can we resolve this emergent crisis with social justice or ecological reciprocity? Can we even eliminate or mitigate violence with acts of human kindness? More crucially, can designers address how people treat each other and our living ecology or will we continue to primarily serve a mass marketplace of individual wishes? If we are at a punctuation point in evolving design practices, can designers adopt new goals that subvert their own process, progress or success?

We are Much Obliged. Is it too late to accept the greater role of citizen designer exemplified by the utilitarian legislator Benjamin Franklin, and too soon to be the universal citizen Buckminster "Start with the universe" and "If the results are not beautiful, I know I am not done" [2] Fuller? Now is always the opportune moment to crack the code of design, reveal its potential and reform our praxis. As anyone who has planted a tree knows, the best time to plant a tree is twenty years ago.

The second-best time is now.

\section{Manifesto Destiny?}

The recent surge in popularity of design has prompted multiple declarations of the power of design to produce beneficial change and one noble attempt to write a 
manifesto to enact the idea that "All people deserve to live in a well-designed world." [3] Design principles and practices are being celebrated with an invitation to "prototype the future" [4] and dozens of exhortations to innovate, disrupt and change the world. "Utopia Toolbox" [5] catalogs an illuminating collection of such ambitious initiatives. Even the United States Army has incorporated a doctrine of design into its arsenal of weapons to wage persistent war. "In a dynamic and multidimensional operational environment, design offers tools vital to solving the complex, ill-structured problems presented by persistent conflict." [6]

A Bit of Personal History. Fifty years ago, as an impressionable young design student, I spent an inspiring day with R. Buckminster Fuller who told us the goal of design was to "make the world work for $100 \%$ of humanity, in the shortest possible time, through spontaneous cooperation without ecological offense or disadvantage of anyone." [7]

We clearly have yet to accomplish that goal.

Within short months of my infection with Fuller's enthusiasm, I was drafted into the army, ostensibly for the vile war in Vietnam. I rapidly learned some hard lessons about freewill, individual agency, large-scale forces in lethal conflict, destructive power of welldesigned weapons and above all, a spectrum of human behavior well beyond my childhood experiences. Even an aesthetic difference, between the hard kick from the recoil of an M-14 rifle and the easy burping nudges from an automatic $M-16$ rifle, signaled a profound change in my possible relationships to other humans; that signature of a new tragic sense of "self," a "medium," and a realization of the recondite remoteness of the "other."

Something happened. Something broke within me. I mutated.

As a consequence, I became a cynical pragmatist, maybe even a realist. My activism tempered, my idealist fantasies buried, (but latent in every subsequent design consideration) I became host to perhaps an ideal mental brew for pursuing the intelligent response to uncertainty and opportunistic risk management that design, of necessity, becomes.
Design Practices Evolve. What was, in the 19th century, a choice between utility or decoration became, in the 20th century, a focus on synthesis of form and function. By the 21st century, digital tools for design were amplified by revolutions in computing and communication capacity. A fascination with interaction and distribution erupted, permitting designers to develop integrated systems of products and services for "personal" experiences through media design practices.

Since, as Eva Horn has written, "Media are not only the conditions of possibility for events-be they the transfer of a message, the emergence of a visual object, or the re-presentation of things past-but are in themselves events: assemblages or constellations of certain technologies, fields of knowledge, and social institutions." [8]

Old, New (Now), and Eventual. Two lists (see below) of trends in design practices, shared with me by Hugh Dubberly, were the impetus for my speculations on design practice over a decade ago. Extrapolating emergent aspects of design from those two lists spawned the notion of the "eventual". The question of what happens as a consequence of what a thing is and what it does, provoked the idea of turning the attention of designers from objects to events to better understand cause and effect, especially in social behavior.

In the old dominant design paradigm, heroic solo product designers worked on the composition of editions of static objects in a fixed locus (node) using information drawn from computers. They sought simplicity, if not for the sake of the relationship of form and function, at least to make manufacture for massive consumption efficient. Decisions and control followed a top-down hierarchy.

In the new (now), then dominant, design paradigm (in the golden age of the Internet and web) teams of service designers used improvisation and continuous updating of dynamic links to invent experiences using persuasive communication. They embraced and exploited complexity, if not for the sake of tighter relationships of form to belief, at least to enrich interaction and fascination with screens. Decision-making and control 


\section{Old}

$\begin{array}{ll}\text { Product as } & \begin{array}{l}\text { object } \\ \text { static } \\ \text { node } \\ \text { information } \\ \text { computing }\end{array} \\ & \text { with } \\ \text { Key skills } & \text { manufacturing } \\ & \text { product design } \\ \text { Process } & \text { seek simplicity } \\ & \text { solo or hero } \\ & \text { top-down } \\ & \text { editions }\end{array}$

Technique composition

\section{New (Now)}

experience

dynamic

link

persuasion

communicating

through

interaction design

service design

embrace complexity

team

evolutionary

continuous updating

improvisation

\section{Eventual}

\author{
behavior \\ liberal (as in liberating) \\ mesh \\ transformation \\ conversation \\ within \\ etiquette design \\ social networks \\ achieve sophistication \\ community \\ metabolic \\ anticipatory
}

performance
Table 1. Terms in the first three columns (below) are from a memo about design my colleague Hugh Dubberly wrote. They compare Old and New aspects of design. Extrapolating from those two lists and integrating the results yielded my initial notions of eventual design and etiquette. were an evolutionary collective process.

My wishful emergent paradigm proposes, that communities of etiquette designers would use cybernetic conversation to instigate liberal (liberating) behaviors within a mesh of social networks. They would embed sophistication in their design of etiquette, if not for the eventual goal of transforming living systems, at least to improve relationships between semiotic form and social performance. Anticipation would supersede decision-making and control would yield to contextual eventualities and metabolic entailments of events.

Events, Appearances, Performances. Slavoj Zizek postulates an event as when "effects appear greater than apparent causes." [9] An eventual design practice would juxtapose events to consider long and short-term causes, effects and possible consequences, not simply what is or can be.

Events disclose how people choose to invest their attention and how that attention turns into obligations, agreements, appointments, and thereby into actions of life. The salient design question is, “....and then what happens?" Events also significantly occur at and comprise the intersection of information design and experience design practices.

Turning Attention. Can designers invent and deploy a "macroscope" [10] to reveal and mitigate inherent conflicts between nature and human nature? Can the cultural currency of attention find parity or equity with the social currency of trust? Can we conceive and design a common public etiquette for civil society to comprehensively emerge? Can social or ecological justice even be design goals?

It is now possible to trace the events of media from sources to uses and track media incidence to individual experience. Behavioral insights from data-mining permit design of systems to surveil, anticipate, inform and influence individual experience. It may now be possible to assess the impact media have on relations between people.

It should be possible for designers to deploy diagnostic and forensic design research as a reconnaissance of new cultural territory to learn how the spectrum of etiquette between and amongst people can become an index to social justice or design errors. Perhaps this can extend to measuring our collective treatment of our planet's ecology?

It is just barely imaginable that such sophisticated design of media could ultimately engender sustainable beneficial relationships between and amongst humans. However, it does seem feasible to move the attention of designers from the millisecond events between a person and their instant messages, games and signals to other events occurring between and amongst people and to potentially map the consequences of human choices and actions to living systems and nature over deep time. What other success could be more meaningful to civil society?

\section{Etiquette}

How we behave toward others is a spectrum that 
ranges across confluence, collaboration, cooperation, coordination, competition, conspiracy, conflict and coercion. Perhaps a spectrum from fear to love can serve as an index to human treatment of our ecology of living systems; our global common ground?

The writer Guy Davenport recalled Jane Kramer saying that the French "preferred a common etiquette to a common ground." [11] This comment crystallized the idea that social justice in denser diverse populations will require a more sophisticated understanding of the "other" and how to integrate valuable differences in each "other" into society. Adjusting our design scope to examine events opens a portal into how form and significance pass across social synapses and have subsequent or derivative consequences.

Civil society requires, or rather, obliges each individual to acknowledge the value and protect the freedom of the "other." An understanding of "kind" and a common etiquette of kindness is required for negotiation and integration of valuable differences to replace strife and conflict. The real mandate for change of design practice comes from accepting this moral accountability for consequential events of design decisions. Can designers seek such a noble goal when elements of living systems are so complex?

\section{Framing, Forming and Informing a New Design Practice}

Conceptually framing the study of events and the eventual can begin with the "welkin" - the sky we share. Under that sky, the watershed of earth symbiotically grows fuel for life. The equation of life we work within is reciprocity or kinship between logistics of the human project and ecology of living systems. At heart, our concern is action and reaction, between people, and between human nature and nature.

Do we control that symbiosis or will technology beyond our intelligence intervene and mediate living systems?

Logistics. All of human history can be described as a logistical project to support the growth of the human population. An archaic and useful definition of logistics as "what must be known for the conduct of war" [12] helps us see that human project as intrinsically lethal and violent. How we prosecute the human project could be described as a kind of war against nature and struggle against natural forces. But it is actually within us, within the context of evolution. Will we govern our logistics by design, by sentient technology or have we lost even the capacity to govern technology by logic, or ourselves by law or common sense?

Ecology. Our common ground is finite. Our capacity for meanness and kindness seems unlimited. Witness the plight of indigenous hunter-gatherers whose lands are confiscated with the rise of the nation-state. They occupy boxes of concrete that are hot in the summer and cold in the winter. With the arrival of subsidized and mandated provision of electricity, they obtain refrigerators. With refrigerators, they obtain soft drinks. With a diet of soft drinks, they obtain diabetes, further decimating their population. This in all of ten years out of thousands living sustainably. The spectrum of etiquette includes ecologic cruelty.

Kinship. When James Grier Miller, instrumental in formulating behavioral science, wrote "General Living Systems Theory," he was inviting the social sciences to find a way to join with the natural sciences to better "understand the facts of life." [13] He invoked cybernetics as a tool for accomplishing that and, more importantly, identified and defined a systems approach to the natural ecology that permitted examination of how society might achieve civilization in concert or kinship with nature; a kinship monitored within events. Kinship and Kindness. Kindness is a social solvent. Kindness also requires a study of difference. To integrate valuable differences in situations or events one must understand kind. Kindness may turn out to be crucial to the survival of the fittest when we consider our social interdependence. Behavioral economics might explain our neglect.

Aesthetics. Beyond physical reflexes, humans have evolved and embody a system of signs, the semiotics of everyday life, as a counterpoint to the physics of everyday life. These signs mediate between the metabolic and cybernetic systems which govern everyday life. The aesthetic goal for individual and social experience would be for events to dissolve into timeless 
moments. For this, we need to better understand the link, the kinship, between aesthetics and etiquette.

\section{Timebase over Database. As a time-based meta-} practice, eventual design would work by coordination, configuration and sequencing of events; with temporalities, appointments, assignments, and notions of subjective and elastic time. All of the qualities and paradigms of time delineated by Olga Ast in "Fleeing from Absence" [14] enter into consideration. Events can act as armatures for prototyping ideal living systems, but how can we account for all the entailments of events?

Technological Feasibility. Bruno LaTour said it: "New innovation will be absolutely necessary if we are to adequately represent the conflicting natures of all the things that are to be designed...visualization tools that allow the contradictory and controversial nature of matters of concern to be represented." [15] At a minimum we might reform architectures of computation and communication to employ parallelism, connectome mapping, record/playback, fuzzy and three-state logic, data valencing, metabolic processing, photonic switching, fractal zooming, depiction morphing, consideration spacing and pacing, sociocratic programming, blockchain accounting, link typing, quantum computing and sensitivity modelling in an event laboratory larger than the experiment.

Temporal Nominal Annotation. The construct of the tenome I imagine could begin to monitor a temporal membrane across which stories are told, lives are lived, and histories are narrated. While the genes and memes circulate in matter and memory, their intersection in time as social interactions might be marked in a tenome. A carefully annotated tenome could locate and score the interstitial event, where media disappear, and exchange of cultural and social values takes place.

The site of exchange could even permit value to be extracted by a mediator, the way a bitcoin miner is compensated. Knowing what to do next; the etiquette, [16] or reading choices offered by the "ticket" could emerge from data within the tenome.

Templates of tenomes (see below) would be a possible way of marking time, annotating situations and mapping scenarios for deliberation, analysis and sharing insights. (Binary systems, which now tend to "eat their young," should evolve such consideration space/time to more naturally integrate with lives, as lived, of human beings.)

For Example. When the replacement of the decayed planks of a park bench is connected to a decision to plant a tree decades in advance, and the construction of the bench permits this repair to be a social event; a sense of continuity and community ensues; a natural order is preserved and enjoyed.

When that kind of knowhow and understanding is conveyed over generations, a sophistication is embedded in the designing and deciding that subdues violence. A pragmatic, yet noble transaction occurs when preparedness has replaced planning

\section{Event Markers and Maps}

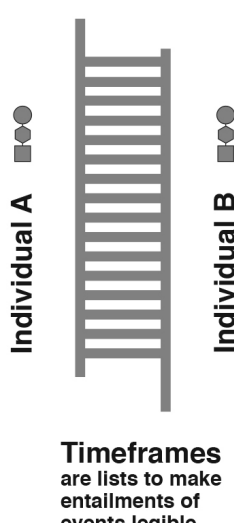

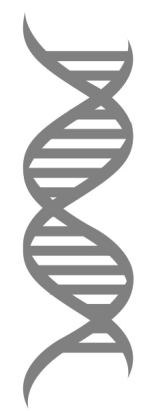

Tenomes

are frames twisted to reveal time cycles.

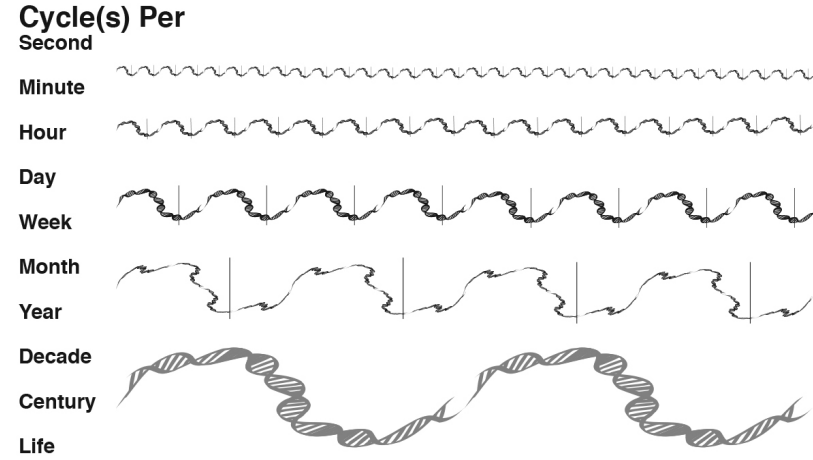

Events as Potential Moments

Marking direct and mediated interactions between people, media and machines. Locating consequences, origins, causes and effects.
Figure 1. Schematic of

a method for marking

a time-base as events

between sender and

receiver. Entailments of

the event listed, and time

cycles twisted into time

frames assist in seeing

chronology, sequence

or series. Parallelism

would reveal potential

correlations. 
and the eventualities of nature are respected and accommodated. The persistent practical question is simply, “...then what happens?" or "Great, now what?"

\section{The Goals of Eventual Design}

Eventual design is proposed as a meta-practice to address situations of human experience between and amongst people within the logistics and ecology of an emergent world. Its praxis is a holistic investigative approach to design of mediating form, that begins within an imaginary, but necessary, School of Behavioral Arts, where all disciplines or practices exploring, employing and deploying the human body convene. There, a study of form and function, form and belief and form and behavior, seeks to understand life as a performance and discover essential, optimal and eventual relationships between form and fruition.

Identifying. Events link cause and effect. Events hold clues to quantum entanglements. Events signify and illuminate life. Events, from geologic to nanosecond, mark time. Events convey cultural signals. Chains of events link deep history, inheritances and influences.

Mediating. Form affects behavior. Designing form that mediates between people can establish and enhance etiquette. The test? If the interface, artifact, experience, behavior feels rude, it is rude.

Monitoring. Relationships between the logistics of the human project and the ecology of living systems over deep time can be registered as interdependent and assessed for consequence, and eventualities located.

When in the Course of Human Events. Fuller likened design to electricity, writing "We cannot define it, but we can measure its effects." [17] Yet despite recent advancement of design research, we seldom measure effects or aftereffects of design, nor do we have useful metrics for effects we observe. Instead, we rely on market forces to reward and punish the work of designers.

The emergent situation of the present world poses challenges neatly articulated by a truly global explicitly and implicitly violent force, the U.S. military as:

"Globalization, technological diffusion, demographic shifts, resource scarcity, climate changes and natural disasters, proliferation of weapons of mass destruction, and failed or failing states." [18] Add density of human habitat, and ubiquitous digital connectivity to compress reaction times and accelerate recoil. Any design renaissance that alleviates yet untreated problems of the planet will require a sophisticated reconnaissance of actual and potential consequences. A quantum shift of attention from object to event, from information database to human time-base, offers a way to seek and evaluate such correlations, causes, effects and consequences.

You are Invited to an Otherwise Future. Ideally, designers would develop formal systems that advocate, enable, distribute and sustain social justice; where inherent conflicts of human nature within our common ground are resolved; where the form and content of infrastructure, artifacts, and appliances establish, inform and evolve a common universal etiquette that reconciles human nature with other wisdom. The daunting complexity of living systems, our growing interdependence as humans, and with technologies that animate and emulate life, constitute our event laboratory.

I cordially invite you to enter.

Acknowledgements. Hugh Dubberly's list of trends in design practice provoked my speculations. Eliot Z. Felde gave astute advice on voice and emphasis, and Kate Terrado insisted I clarify my scattered thoughts. Any failure to do so is mine alone.

\section{References}

1. Cavell, Stanley. (2013). This New Yet Unapproachable America: Lectures after Emerson after Wittgenstein. University of Chicago Press.

2. Fuller, R. B. (1972, 1969). Utopia or Oblivion: The Prospects for Humanity. Bantam Books

3. World Design Summit. (2017). http://www designdeclaration.org/declaration/

4. Land der Ideen, GmbH. (2019). https://land-der-ideen.de/en/ competitions/beyond-bauhaus

5. Stiegele, J., Tobier, N. (2015). Utopia Toolbox: An incitement 
to radical creativity. STAMPS.

6. Department of the Army (26 March 2010). Field Manual No. 5-0. Headquarters, Washington, DC. Chapter 3, p. 4.

7. Fuller, R. B. (1972, 1969). Utopia or Oblivion: The Prospects for Humanity. Bantam Books.

8. Horn, E. (2007). Editor's Introduction: "There Are No Media", Grey Room, No.29. pp. 6-13.

9. Žižek, S. (2014). Event. London: Penguin.

10. de Rosnay, J. (1979). The Macroscope: A New World Scientific System. Harper \& Row, New York.

11. Davenport, G. (1996). The Hunter Gracchus and Other Papers on Literature and Art. Counterpoint.

12. Webster's New Twentieth Century Dictionary of the English Language, Unabridged, (1950). The Publishers Guild, New York. p. 1002.

13. Miller, J. G. (1970). The Nature of Living Systems: An Exposition of the Basic Concepts in General Systems Theory. Distributed by ERIC Clearinghouse.

14. Ast, O. (2009). Fleeing from Absence. Olga Ast Books.

15. Latour, B. (September 2008). A Cautious Prometheus? A Few Steps Toward a Philosophy of Design (with Special Attention to Peter Sloterdijk). Keynote lecture for the Networks of Design meeting of the Design History Society. Falmouth, Cornwall.

16. Webster's New Twentieth Century Dictionary of the English Language, Unabridged, (1950). The Publishers Guild, New York. p. 600.

17. Fuller, R. B. (1972, 1969). Utopia or Oblivion: The Prospects for Humanity. Bantam Books.

18. Department of the Army (26 March 2010). Field Manual No. 5-0. Headquarters, Washington, DC. Chapter 3, p. 4. 